\title{
Chinese researchers told to fend for themselves
}

Beijing. China wants two-thirds of the scientists it now funds to find other sources of support as part of the movement towards a free-enterprise system. But many of the 80,000 researchers at hundreds of government-funded institutes believe that the policy fails to account for the varying appeal to industry of some of their work.

They are concerned that the new policy, if not modified, will mean that researchers in some fields will be forced to abandon their profession. While researchers at the Changchun Institute of Applied Chemistry within the Chinese Academy of Sciences, for example, can be expected to fend for themselves, those at the Geosciences Institute and the Desert Research Institute will have a much harder time of it.

The new philosophy was spelled out in late August by the State Science and Technology Commission. Its goal is to give China a modern research and development network that is well-balanced, efficient and vigorous. Its elements include diversifying talent, stabilizing basic research, increasing the number of high-technology projects, creating high-technology enterprises and preserving existing strengths in basic and applied research.

China's policy-makers believe that new initiatives such as the Climbing programme (see Nature 359, 177; 1992) and the 863 high-technology programme are sufficient to keep China at the forefront of global science. Zhou Guang-Zhao, president of the Chinese Academy of Sciences, is fond of saying that these efforts will allow China "to win gold medals in the world science olympics".

But Zhou's optimism is not shared by most working scientists, who can be overheard at conferences talking about opening restaurants and running shops after state funding is cut off. In an effort to remain viable, the National Geology Library of China has rented out half of its building to a local company, for a fee of 2 million yuan (US\$350,000). Unfortunately, the loss of such an important resource can only hurt those left to practise science.

It is not clear whether the new policy is part of a long-term strategy or merely a short-term expedient to withstand the current worldwide recession. Although the government has promised to increase significantly the salaries of those who retain funding, many researchers say that the policy raises questions about the government's commitment to science at any price.

You Qin Li

\section{Japanese increase spending on universities}

Tokyo. One per cent of a supplementary budget approved last week by the Japanese cabinet to boost the faltering Japanese economy will be spent on buildings and facilities at government research organizations.

A senior official of Tokyo University, Japan's leading national university, says the supplementary budget is "wonderful news" but that no spending decisions have been made. The universities received a similar windfall in 1987, at the time of the last major supplementary budget, and much of the money was invested in supercomputers and new buildings. The new allocation is for the fiscal year that ends on 31 March 1993.

The biggest beneficiary of science’s $¥ 113$ billion (nearly US\$1 billion) share of a onetime $¥ 10,700$ billion supplementary budget is the Ministry of Education, Science and Culture, which will get an extra $¥ 82.5$ billion for the national universities, universityrelated research institutes, private universities, technical colleges and museums. This is separate from $¥ 20$ billion a year for the next five years already set aside in the ministry's budget to rebuild national universities (Nature 355, 99; 1992) with money derived from selling land owned by them.

The Science and Technology Agency (STA) gets an extra $¥ 17.8$ billion, of which $¥ 5$ billion is for buildings and facilities, including $¥ 1.5$ billion for imported scientific equipment. The remaining money will go to several projects, including the world's most powerful synchrotron, Spring-8, being built in Harima science park, installing seismographs 2,000-3,000 metres underground for earthquake prediction, the Japanese contribution to the US space station and STA's marine and radiological research institutes.

The Agency of Industrial Science and Technology, the main research arm of the Ministry of International Trade and Industry, plans to spend its $¥ 12.7$ billion to shorten by one year construction of two institutes in Tsukuba science city that are part of a reorganization of four of the agency's institutes there (Nature 351, 90; 1991). The two institutes - for materials science and life science - had been expected to be completed in fiscal year 1994. Some of the new money will be used for laboratory equipment and cooling systems that do not contain chlorofluorocarbons. David Swinbanks

\section{NIH plans trials of controversial AIDS drug}

Washington. Bowing to pressure from African-American activist groups, the US National Institutes of Health (NIH) last week agreed to go ahead with governmentsponsored clinical trials of oral interferon alpha in AIDS patients.

The government has been accused of ignoring or suppressing evidence that the drug, which goes under the names Kemron, Immunex or Immuviron, is effective in treat-

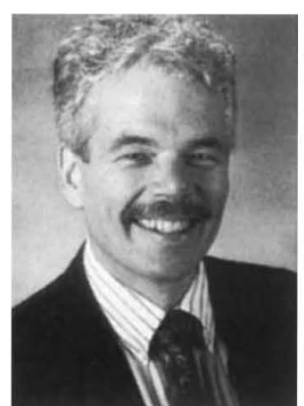

Jack Killen ing AIDS symptoms (see Nature 359, 661; 1992). It has become a cause celèbre for African-American groups, led by the Nation of Islam, after some early uncontrolled clinical trials in Kenya generated reports of dramatic but subsequently unconfirmed results, including serodeconversion.

NIH officials met researchers and African-American doctors who have been working with the drug and announced afterwards that the evidence - both scientific and anecdotal - justified taking interferon alpha to full clinical trial. The next step, according to Jack Killen of the National Institute of Allergy and Infectious Diseases, is a plan to conduct the trials, to be developed in the next few months with help from an advisory panel. Current thinking is for a minimum of three sites at a cost of several million dollars. Barbara Justice and Abdul Alim Muhammad, two doctors affiliated with the Nation of Islam who have been prescribing interferon alpha to their AIDS patients for the last year, are expected to be members of the panel.

Despite NIH's approval, the issue remains controversial. Much of last week's closed meeting, according to participants, was focused not on data but on accusations of "genocide" and racism, some levelled at NIH officials.

NIH based its decision to proceed on data provided by Wilbert Jordon of King-Drew Medical Center in Los Angeles. Jordon reported that, in head-to-head trials of four groups taking AZT, low-dose Kemron, a placebo, or a combination of AZT and Kemron, only the Kemron-only group showed improved CD4 counts after one year. Although the data need further examination, they offer NIH enough evidence to justify taking the next step and relieving, for the moment, the political pressure on the agency.

Christopher Anderson 